\title{
ВОЗМОЖНОСТЬ ИСПОЛЬЗОВАНИЯ ЗОЛЫ ПРОМЫШЛЕННЫХ КОТЛОВ ПРИ ДОЗИРОВАНИИ КОНСТРУКЦИОННОГО БЕТОНА
}

\section{ОРИГИНАЛЬНАЯ СТАТЬЯ}

JUSTINO, Lucas Diego de Souza ${ }^{1}$

JUSTINO, Lucas Diego de Souza. Возможность использования золы промышленных котлов при дозировании конструкционного бетона. Revista Científica Multidisciplinar Núcleo do Conhecimento. Год 06, эд. 09, Vol. 02, с. 81-97. Сентябрь 2021 года. ISSN: 2448-0959, Ссылка доступа: https://www.nucleodoconhecimento.com.br/гражданскоестроительство/конструкционного-бетона,

DOI: 10.32749/nucleodoconhecimento.com.br/ru/97183

\section{СВОДКА}

Индустриализация $и$ ускоренный рост населения порождают побочные эфрфекты на различные социальные аспекты, а экологическая проблема вызывает беспокойство из-за последствий, вызванных социальной эволюцией. Управление промышленными отходами является большой проблемой, которая включает в себя как контроль за их образованием, так и надлежащую утилизацию, обеспечивая экологическую устойчивость. Зольный остаток котла встречается в изобилии на заводах, которые используют это оборудование для выработки пара. Такое изобилие возникает из-за отсутствия места для надлежащей утилизации или повторного использования остатка. Учитывая этот сценарий, в этой статье в качестве ориентира был вопрос: можно ли использовать этот остаток при производстве конструкционного бетона? Целью данного исследования была классификация остатка путем определения его возможной формы использования в дозировке бетона и выполнение

\footnotetext{
${ }^{1}$ Окончил факультет гражданского строительства. ORCID: 0000-0003-2630-8866
}

RC: 97183

Доступно в: https://www.nucleodoconhecimento.com.br/гражданскоестроительство/конструкционного-бетона 
экспериментальных доз с использованием промышленной золы котла для оценки его возможного технического вклада в основные свойства бетона. Для этого образцы были собраны промышленностью, установленной в городе Uberlândia, штат Minas Gerais, действующей в нескольких секторах, таких как сельское хозяйство, корма для животных, фрармацевтика и другие. Классификация зол котла проводилась путем применения бразильских нормативных процедур и параметров, используемых для классификации связующих и заполнителей для бетона. Учитывая его гранулометрическую кривую и плотность, остаток был классифицирован как легкий и очень тонкий агрегат, таким образом, приняв методологию частичной замены тонкого заполнителя золой котла. Было проверено снижение обрабатываемости бетона в свежем состоянии пропорционально содержанию использованных остатков. Поэтому необходимо использовать добавки суперпластификатора в этих случаях для поддержания ожидаемой обрабатываемости. Снижение плотности бетона было замечено при использовании остатка, считая необходимым внимание к этому свойству бетона по отношению к содержанию используемого остатка в дозировке. Также было отмечено при сравнении дозировок с использованием остатка при стандартной дозировке, что наблюдалось снижение прочности на сжатие. Тем не менее, не было больших различий в прочности сжатия между дозировками с различными уровнями замещения. Поэтому был сделан вывод о том, что, учитывая уровни, использованные в данном исследовании, целесообразно использовать этот остаток в производстве конструкционного бетона.

Ключевые слова: бетон, биомасса, зола промышленного котла.

\section{1. ВСТУПЛЕНИЕ}

Промышленная революция, начавшаяся в Англии в 18 веке с создания парового двигателя шотландским инженером James Watt, способствовала британской индустриализации с целью преобразования производственной

$\mathrm{RC}: 97183$

Доступно в: https://www.nucleodoconhecimento.com.br/гражданскоестроительство/конструкционного-бетона 
системы. Этот период, по мнению Cavalcante (2011), «был предшественником капитализма, то есть перехода от коммерческого капитализма к промышленному капитализму». Это означает, что в этом контексте ранее использовавшийся производственный режим заменяется режимом счетовфрактур макино, что приводит к гораздо более гибким производственным процессам, способным применить массовое производство на практике, обеспечив большую поставку продукции и низкие производственные затраты по сравнению с предыдущим сценарием.

Преобразования, произошедшие во время промышленной революции, распространились во всем мире и сопровождали эволюцию общества с течением времени, модернизируя и совершенствуя производственные практики на протяжении многих лет. Однако с прогрессом процесса индустриализации, ростом мирового населения и, следовательно, высоким спросом на продукцию, потребление природных ресурсов растет пропорционально этому спросу, поскольку эти ресурсы служат сырьем для производственных процессов.

Таким образом, ускоренный процесс роста порождает в качестве побочных эфрфектов воздействие на окружающую среду, вызванное эксплуатацией природных ресурсов, без надлежащего управления, ориентированного на поддержание и сохранение окружающей среды. «Эксплуатация природных ресурсов стала хищнической в пользу получения капитала» (GANZALA, 2018).

Негативные последствия индустриализации на протяжении 20-го и 21-го веков, связанные с окружающей средой, связаны не только с неустойчивым потреблением природных ресурсов, участвующих в производственных процессах, но и с загрязнением воды, почвы и воздуха, вызванным отходами или отходами, образуемыми в результате промышленных процессов. Такая реальность наблюдается как в развитых, так и в развивающихся странах.

$\mathrm{RC}: 97183$

Доступно в: https://www.nucleodoconhecimento.com.br/гражданскоестроительство/конструкционного-бетона 
В нескольких промышленных процессах используется оборудование, называемое паровыми котлами, в производственном процессе различных сахарных и спиртовых производств, сушильных и паробогатых заводов зерна, холодильников, металлургической промышленности, текстиля и в секторе производства энергии. Наиболее распространенным типом котла, используемого в настоящее время, является так называемый котел на биомассе. Эти котлы используют в качестве материала для сжигания различные фрормы биомассы, такие как: сосна, эвкалипт, рисовая шелуха и багасса сахарного тростника. После сжигания биомассы зола котла образуется в качестве отходов, поэтому зола котла состоит из горючей части, присутствующей в составе биомассы, используемой в качестве топлива в промышленных котлах.

Отрасли, использующие котлы, стремясь к энергоэффрективности и экономическому фактору, применяют контроль процессов сжигания биомассы, которые максимально снижают образование этого вида отходов. Однако образование отходов неизбежно в этом процессе. Поэтому наличие этого остатка становится обильным. В этих отраслях промышленности накапливаются крупные залежи этого материала из-за отсутствия альтернатив для назначения или повторного использования его. Эти месторождения занимают большие фризические пространства на производственных предприятиях, которые можно было бы лучше использовать, учитывая конечную деятельность рассматриваемой отрасли.

В случае, когда было обнаружено, что высокий уровень доступности серого остатка котла и отсутствие подходящего места захоронения или деятельности для повторного использования остатка, возникает фундаментальный вопрос для разработки этого исследования: можно ли использовать этот остаток в производстве конструкционного бетона? Учитывая ускоренные темпы развития строительного сектора и его поиск инноваций, образующиеся отходы могут

$\mathrm{RC}: 97183$

Доступно в: https://www.nucleodoconhecimento.com.br/гражданскоестроительство/конструкционного-бетона 
быть повторно используются в этом сегменте в качестве устойчивой альтернативы с возможностью содействия техническим и экономическим выгодам как для отрасли, производящей отходы, так и для компаний, производящих бетон.

Экологический вклад является основным и наиболее значительным достижением с использованием зольного остатка от промышленных котлов при производстве конструкционного бетона, поскольку был бы двойной экологический вклад во избежание удаления отходов в окружающую среду, и, если бы была проверена возможность его применения в качестве частичной замены природных заполнителей, это позволило бы избежать извлечения части этих природных ресурсов, которые становятся все более редкими.

Бетонодобывающие компании имеют в качестве характеристики использование сырья, то есть без необходимости крупных процессов переработки, таких как природные пески, которые извлекаются из рек или месторождений, и требуют простой обработки, такой как просеивание для удаления примесей и классификация размеров частиц. Таким образом, использование отходов в бетонном производстве имеет экономический вклад как в отходообразующую промышленность, которая обеспечивает отходы без необходимости крупных процессов переработки, так и для компаний-производителей бетона, которые выиграли бы от высокой доступности отходов и их низкой стоимости, используемых в качестве сырья при их производстве.

Общей целью данного исследования является выполнение предварительной классификации зольного остатка промышленного котла, определение его возможного способа применения в дозировке бетона, выполнение экспериментальных дозировок для проверки выполнения основных свойств дозированного бетона с использованием стульной золы, оценка возможных технических вкладов и, наконец, заключение целесообразности использования этого остатка для дозировки конструкционного бетона.

$\mathrm{RC}: 97183$

Доступно в: https://www.nucleodoconhecimento.com.br/гражданскоестроительство/конструкционного-бетона 


\section{2. МЕТОДОЛОГИЯ}

Первоначальная концепция возможности целесообразности использования котловой золы для производства бетона возникает из идеи, что первоначально в бетонном производстве использовались только три основных материала: цемент, заполнитель и вода. Однако для лучшей производительности как в свежем, так и в закаленном состоянии было инициировано применение химических добавок. Через некоторое время использование цементных материалов органической природы было введено в этом контексте в качестве добавок к смеси бетона в виде гранулированного дробеструйного шлака, пуццоланов, кварцевого дыма и летучей золы.

Первоначальные причины использования этих материалов обычно были экономичными: они стоили дешевле, чем Portland цемент, часто потому, что они существовали в природных месторождениях, требуя мало или вообще никакой обработки, в других случаях потому, что они были побочными продуктами или бракованием промышленных процессов (NEVILLE, 1997, стр. 81).

«Летучая зола является результатом котлов в процессе сжигания угля, в которых часть минерального вещества кластерится, образуя золу сетки, но большая ее часть тащится выхлопным током газа, который называется летучей золой» (MEHTA; MONTEIRO, 1994).

Это исследование было проведено в апреле 2021 года посредством исследований инноваций для сегмента производства бетона в регионе Uberlândia, штат Minas Gerais, где наблюдалось большое количество отраслей промышленности, установленных в этой местности, которые использовали котлы в качестве средства выработки пара в своих производственных процессах и, таким образом, существует большая доступность золы котла, а также большая потребность в надлежащем экологическом удалении или повторном утилизации отходов.

$\mathrm{RC}: 97183$

Доступно в: https://www.nucleodoconhecimento.com.br/гражданскоестроительство/конструкционного-бетона 


\section{1 ОТБОР ПРОБ И ХАРАКТЕРИСТИКА ЗОЛЫ}

Образец материала, использованного в этом исследовании, был предоставлен крупной промышленностью, установленной в муниципалитете Uberlândia, штат Minas Gerais, работающей в нескольких секторах, таких как сельское хозяйство, корма для животных, фрармацевтика и другие. Зола, образующаяся в результате процесса сжигания эвкалиптовой биомассы, смешивается с водой, чтобы избежать атмосферного рассеивания, и проводится в процессе декантирования, где был собран образец. Таким образом, собранный материал имеет высокое содержание влаги, визуально подтвержденное свободной водой, присутствующей поверхностно в собранном образце, в дополнение к воде, поглощенной самим материалом.

После сбора образца и его доставки в лабораторию материалов был проведен процесс сушки материала, чтобы начать его определение основных характеристик. Из-за высокого содержания влаги, наблюдаемого в образце, процесс сушки необходимо было начинать с распределения материала на открытом воздухе по пластиковому покрытию, избегая загрязнения и рассеивания. После частичной сушки на открытом воздухе материал помещали в печь для завершения процесса сушки.

Индекс тонкости определяли по номеру сита 200, согласно NBR 11579 ABNT (2012). В ходе выполнения этого испытания было замечено, что в материале, удерживаемом в сите № 200, большинство из них состояло из тонкого материала, но наблюдалось присутствие частиц с большими размерными размерами частиц, но в небольшой пропорции. Индекс тонкости материала составил 46\%. Этот индекс был признан высоким, по сравнению с портландцементом, который имеет этот максимальный индекс $10 \%$, установленный NBR 16697 (ABNT, 2018).

RC: 97183

Доступно в: https://www.nucleodoconhecimento.com.br/гражданскоестроительство/конструкционного-бетона 
Кажущаяся удельная масса определялась по NM 52 ABNT (2009). Зола

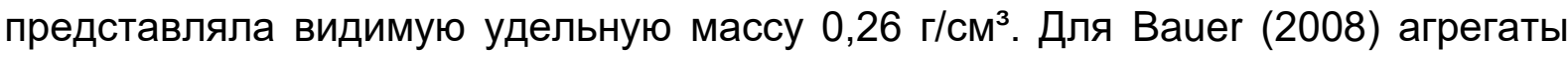
могут быть классифицированы в соответствии с их удельной массой. Поэтому зола была классифицирована в этом аспекте как легкий агрегат, а обнаруженный удельный вес был эквивалентен удельной массе легких агрегатов, известных, как пример легкого агрегата вермикузиту, который имеет удельный вес 0,3 г/см³.

Гранулометрическую характеристику проводили по NBR NM 248 ABNT (2003). Зола представлена гранулометрическим распределением согласно таблице 1, модуль тонкости 0,74 и максимальный размер 1,2 мм.

Таблица 1 - Серое гранулометрическое распределение котла

\begin{tabular}{|l|l|l|}
\hline $\begin{array}{l}\text { Сито \# } \\
\text { (мм) }\end{array}$ & Удержанные (\%) & Накопленные (\%) \\
\hline $\mathbf{2 , 4}$ & 0,80 & 0,80 \\
\hline $\mathbf{1 , 2}$ & 2,47 & 3,27 \\
\hline $\mathbf{0 , 6}$ & 5,74 & 9,01 \\
\hline $\mathbf{0 , 3}$ & 12,23 & 21,24 \\
\hline $\mathbf{0 , 1 5}$ & 18,43 & 39,67 \\
\hline Дно & 60,33 & $* * *$ \\
\hline
\end{tabular}

Источник: Автор (2021).

Основываясь на проверенных основных характеристиках, мы попытались назначить первоначальную классификацию золы для определения фрормы ее применения в конкретных дозировках. Первоначально были рассмотрены две возможности, описанные ниже.

$\mathrm{RC}: 97183$

Доступно в: https://www.nucleodoconhecimento.com.br/гражданскоестроительство/конструкционного-бетона 
Первая возможность использования золы будет заключаться в том, чтобы включить ее в дозировку бетона в качестве дополнения, начиная с добавления материалов в качестве примера активного кремнезема, широко используемого в производстве высокоэффективного бетона и для потенцирования специфических свойств бетона, таких как механические сопротивления, в основном. Однако из-за верифицированного профиля золы при определении ее показателя тонкости и гранулометрического распределения такая возможность была исключена из-за несовместимости ее характеристик с данным видом добавки.

В качестве второй возможности использования золы было проверено ее возможное введение в качестве замены заполнителей в дозировку бетона. Результаты, полученные по отношению к удельной массе, были соблюдены и, как уже сообщалось, он был оформлен в виде легкого агрегата. Другой характеристикой, проанализированной с учетом такой возможности использования, стала классификация золы по отношению к гранулометрическому диапазону, в котором она была оформлена, на основе таблицы 2.

Таблица 2 - Классификация песков по гранулометрическим диапазонам

\begin{tabular}{|c|c|c|c|c|}
\hline $\begin{array}{l}\text { Нераспределенные } \\
\text { проценты }\end{array}$ & & & & \\
\hline Сита (мм) & $\begin{array}{l}\text { Трек } 1 \text { - } \\
\text { Очень } \\
\text { тонкий }\end{array}$ & $\begin{array}{l}\text { Трек } 2 \text { - } \\
\text { Тонкий }\end{array}$ & $\begin{array}{l}\text { Трек } 3 \text { - } \\
\text { Средний }\end{array}$ & $\begin{array}{l}\text { Трек } 4 \quad- \\
\text { Толстый }\end{array}$ \\
\hline 6,3 & от 0 до 3 & от 0 до 7 & от 0 до 7 & от 0 до 7 \\
\hline 4,8 & от 0 до 5 & от 0 до 10 & от 0 до 11 & от 0 до 12 \\
\hline 2,4 & от 0 до 5 & от 0 до 15 & от 0 до 25 & от 5 до 40 \\
\hline 1,2 & от 0 до 10 & от 0 до 25 & от 10 до 45 & 30 до 70 \\
\hline
\end{tabular}

RC: 97183

Доступно в: https://www.nucleodoconhecimento.com.br/гражданскоестроительство/конструкционного-бетона 


\begin{tabular}{|l|l|l|l|l|}
\hline $\mathbf{0 , 6}$ & от 0 до 20 & $\begin{array}{l}\text { от } 21 \text { до } \\
40\end{array}$ & 41 до 65 & 66 до 85 \\
\hline $\mathbf{0 , 3}$ & 50 до 85 & 60 до 88 & 70 до 92 & 80 до 95 \\
\hline $\mathbf{0 , 1 5}$ & 85 до 100 & 90 до 100 & 90 а100 & 90 до 1 \\
\hline
\end{tabular}

Источник: Bauer (2008).

Гранулометрическое распределение золы, представленное в таблице 1, не было полностью оформлено ни в одном из классификационных диапазонов, описанных в таблице 2. Однако были отмечены характеристики, сходные с распределением, классифицированным как трек 1 - Очень тонкий, соответствующие этому диапазону процентов, сохраненных в ситах с открытием 2,4 мм, 1,2 мм и 0,6 мм. В других ситах удержанные процентные показатели оставались ниже указанных в таблице 2.На дне ситового ряда наблюдалась высокая концентрация материала, т.е. прохождение материала в сито с отверстием 0,15 мм.

Таким образом, было проверено, что зола имеет гранулометрическое распределение очень близко к полосе 1 - Очень тонкий, но со значительным процентом материала тоньше, чем прогнозировалось В этом гранулометрическом диапазоне, то есть тяготеет к предыдущему диапазону, если таковой имелся.

Модуль тонкости 0,74, полученный гранулометрической характеристикой золы, как уже сообщалось, усилил классификацию золы в диапазоне перед полосой 1 - Очень тонкий, поскольку минимальный модуль тонкости для классификации в этом диапазоне составит 1,35 (BAUER, 2008).

В связи с несовместимостью золы с показателем тонкости традиционно используемых добавок и их частичной классификацией как очень тонкого

RC: 97183

Доступно в: https://www.nucleodoconhecimento.com.br/гражданскоестроительство/конструкционного-бетона 
заполнителя, мы решили, следовательно, изучить возможность замены очень тонких заполнителей золой в дозировке бетона.

\section{2 СТАНДАРТНЫЙ ХОД И УРОВНИ ЗАМЕНЫ}

Определение признака, который будет использоваться в качестве стандарта, было основано на характеристиках золы, определенных ранее. Штрих по умолчанию должен содержать в своем составе агрегат, классифицированный как очень тонкий, который будет заменен серым.

Увеличение расхода воды в дозировке за счет добавления золы было предметом внимания при определении стандартного удара, поскольку с учетом предупреждения Neville (1997) «зола рисовой соломы имеет сложные фрормы, в зависимости от растения происхождения и, следовательно, требует много воды»,, было отмечено время, необходимое для сушки образца золы котла, и было сочтено, что из-за ее происхождения и удельной поверхности, возможно, добавление золы увеличит потребление воды в дозировке по отношению к стандартной дозировке.

Для борьбы с увеличением расхода воды в дозировках с добавлением золы Neville рекомендует (1997) использовать добавки суперпластификатора для достижения ожидаемой обрабатываемости. Поэтому мы решили определить стандартный признак с использованием этого вида добавки.

Стандартный ход был принят с требуемой прочностью на сжатие 25 МРа и рассеянием между 600 и 650 мм, определенным в соответствии с NBR 15823-2 ABNT (2017). Для единицы массового признака были найдены следующие пропорции: $1: 0,59: 2,21: 1,11: 2,60$, при соотношении a/c, равном 0,58, получено количественное для перемешивания согласно таблице 3.

Таблица 3 - Стандартный ход 25.0 МРа Рассеяние от 600 до 650 мм

$\mathrm{RC}: 97183$

Доступно в: https://www.nucleodoconhecimento.com.br/гражданскоестроительство/конструкционного-бетона 


\begin{tabular}{|l|l|l|}
\hline Цемент & $\mathbf{1 0}$ & Кг \\
\hline Очень мелкий песок & 5,88 & Кг \\
\hline Средний песок & 22,10 & Кг \\
\hline Гравий 0 & 11,12 & Кг \\
\hline Гравий 1 & 25,96 & Кг \\
\hline Пластифицирующая добавка & 0,035 & Л \\
\hline $\begin{array}{l}\text { Добавка } \\
\text { суперпластификатора }\end{array}$ & 0,10 & Л \\
\hline Вода & & \\
\hline
\end{tabular}

Источник: Автор (2021).

Заполнитель, названный в таблице 3 «очень мелким песком», был агрегатом, принятым в качестве заменяемого золой котла. Агрегат представлен в его гранулометрическом распределении, модуль тонкости 1,42, классифицированный в гранулометрическом диапазоне 1, который содержит агрегаты с модулем тонкости от 1,35 до 2,25. Поэтому он был классифицирован как очень тонкий агрегат (BAUER, 2008).

Частично была выполнена замена очень мелкодисперсного заполнителя золой, т. е. принятие случайных и прогрессивных уровней замещения, чтобы спровоцировать наблюдение за возможными влияниями, вызванными заменой агрегата золой котла. В качестве отправной точки были приняты уровни замещения $10 \%, 20 \%$ и $30 \%$ на очень тонкой совокупной массе, присутствующей в стандартной дозировке признака, уже представленной в таблице 3.

В таблице 4 показаны признаки единицы массы, принятые для каждого установленного содержания замещения.

RC: 97183

Доступно в: https://www.nucleodoconhecimento.com.br/гражданскоестроительство/конструкционного-бетона 
Таблица 4 - Следы единицы массы, принятые в соответствии с содержанием замены очень мелкодисперсного заполнителя золой котла

\begin{tabular}{|c|c|c|}
\hline $\begin{array}{l}\text { Содержание } \\
\text { золы }\end{array}$ & заполнителя для & Признак единицы измерения массы \\
\hline $10 \%$ & & $\begin{array}{l}1: 0,06: 0,53: 2,21: 1,11: 2,60 \text { a / c = } \\
0,58\end{array}$ \\
\hline $20 \%$ & & $1: 0,12: 0,47: 2,21: 1,11: 2,60 \mathrm{a} / \mathrm{c}=0,58$ \\
\hline $30 \%$ & & $1: 0,18: 0,41: 2,21: 1,11: 2,60 a / c=0,58$ \\
\hline
\end{tabular}

Источник: Автор (2021).

\section{3 ПРОВЕДЕННЫЕ ЭКСПЕРИМЕНТАЛЬНЫЕ ДОЗЫ И ОЦЕНКИ}

Экспериментальные дозировки проводились в лаборатории с использованием стационарного электрического бетономешалки. Сначала стандартный признак был дозирован в таблице 3, а затем другие признаки с соответствующими уровнями замещения, представленные в таблице 4.

В качестве основного критерия оценки были приняты возможные влияния введения котловой золы в дозировки по отношению к свойствам: обрабатываемость бетона в свежем состоянии, плотность и прочность на сжатие.

Для оценки влияния введения золы на дозировку по отношению к обрабатываемости бетона в свежем состоянии проводили анализ во всех дозировках для определения исходной консистенции путем снижения ствола конуса, согласно NBR 16889 ABNT (2020). Первоначальная согласованность, принятая в качестве стандарта, составляла от 40 мм до 60 мм. После достижения исходной консистенции добавку суперпластификатора добавляли к дозировкам с целью повышения обрабатываемости и достижения разброса

$\mathrm{RC}: 97183$

Доступно в: https://www.nucleodoconhecimento.com.br/гражданскоестроительство/конструкционного-бетона 
между 600 и 650 мм, который определялся во всех дозировках согласно NBR 15823-2 ABNT (2017).

Что касается плотности, то она была определена в соответствии с NBR 9833 ABNT (2008).

Оценка прочности на сжатие проводилась с помощью погонажей цилиндрических образцов размерами 10х20мм, согласно NBR 5738 ABNT (2016). Два образца каждой серии были представлены на тест для определения осевой прочности на сжатие в возрасте 7 дней, 14 дней и 28 дней, согласно NBR 5739 ABNT (2018).

\section{4 РЕЗУЛЬТАТЫ И ОБСУЖДЕНИЯ}

В стандартной дозировке признака было замечено, что вода, предсказанная в признаке, была достаточной для достижения первоначальной консистенции, поскольку был получен начальный индекс консистенции 52 мм. Таким образом, в смесь вводили добавку суперпластификатора и устанавливали время перемешивания через 8 минут после дозировки добавки суперпластификатора. Это время смешивания представляет собой среднее время, определенное производителем для рассмотрения полного эфрфекта добавки. После времени перемешивания определяли разбрасывание и в результате получали 620мм, то есть в пределах ранее установленных параметров.

После стандартной дозы следа дозировали с содержанием замены $10 \%$ очень тонкого заполнителя золой котла. В этой дозировке, используя такое же количество воды по отношению к стандартному признаку, был получен начальный показатель консистенции 49мм. В этой связи было отмечено, что внесение золы вызвало незначительное падение первоначальной консистенции бетона. Однако, оставаясь в пределах первоначально установленных параметров, добавку суперпластификатора дозировали и соблюдали

$\mathrm{RC}: 97183$

Доступно в: https://www.nucleodoconhecimento.com.br/гражданскоестроительство/конструкционного-бетона 
стандартное время перемешивания 8 минут, впоследствии определяли разбрасывание и получали 600 мм отверстия.

В последовательности след дозировали с содержанием замены 20\% очень тонкого заполнителя золой котла. При том же количестве воды, которое использовалось в предыдущих дозировках, был получен начальный показатель консистенции 50 мм. С дозировкой добавки суперпластификатора и окончанием стандартного времени перемешивания было разложено отверстие 600 мм, т. е. поведение, очень похожее на предыдущую дозировку, с содержанием замены 10 \% очень мелкого заполнителя золой котла.

Наконец, след дозировался с содержанием замены 30\% очень мелкого заполнителя золой котла. При сохранении количества воды предыдущих дозировок был получен начальный показатель консистенции 38мм, т.е. ниже установленного исходного параметра. В этом случае было замечено, что введение золы в смесь вмешивалось в первоначальную консистенцию, как предупреждал Neville (1997), но мы выбрали последовательность дозирования, потому что полученный первоначальный индекс консистенции был очень близок к установленному нижнему пределу, который составлял 40 мм. После дозировки добавки суперпластификатора и окончания времени перемешивания распределялось 560 мм. Поэтому ниже параметр изначально.

В конкретном случае дозировки с содержанием замещающего 30\% очень мелкого заполнителя золой котла было принято решение увеличить дозировку добавки суперпластификатора с целью достижения минимального заданного зеркального отражения. Поэтому дозировка добавки суперпластификатора была увеличена с 1\% до 1,5\% от массы цемента. После этого добавления добавки в смесь и соблюдения снова времени перемешивания для общего действия добавки, получалось разбрасывание 610мм, то есть подгонка по заранее установленным параметрам.Обрабатываемость является очень важным свойством, потому что «смесь бетона, которая не может быть легко

$\mathrm{RC}: 97183$

Доступно в: https://www.nucleodoconhecimento.com.br/гражданскоестроительство/конструкционного-бетона 
брошена или плотна в своей полноте, не обеспечит ожидаемые прочностные и долговечностные характеристики» (MEHTA; MONTEIRO, 1994).

Плотности, обнаруженные в соответствии с NBR 9833 ABNT (2018), представлены в таблице 5.

Таблица 5 - Определяемые плотности

\begin{tabular}{|l|l|}
\hline $\begin{array}{l}\text { Идентификация } \\
\text { серии }\end{array}$ & Плотность (кг/м³) \\
\hline Стандартный ход & 2335 \\
\hline Tире с 10\% серым & 2078 \\
\hline Тире с 20\% серым & 2070 \\
\hline Тире с 30\% серым & 2066 \\
\hline
\end{tabular}

Источник: Автор (2021).

Было отмечено падение плотности на 11\%, сравнивая стандартный след со следом с содержанием замены 10\% очень мелкого заполнителя золой котла. Для следующих признаков, с уровнями замещения 20\% и $30 \%$, зарегистрированные снижения плотности составили порядка 0,4\% и 0,2\% соответственно, сравнивая анализируемый признак с признаком до него, учитывая постепенный и прогрессивный порядок содержания замены очень тонкого агрегата золой котла.

Результаты испытаний для определения осевой прочности на сжатие представлены в таблице 6.

Таблица 6 - Прочность на сжатие (MPa) по сериям

Сопротивление серии/возрасту/сжатию 7 дней 14 дн. 28 дн. (MPa)

$\mathrm{RC}: 97183$

Доступно в: https://www.nucleodoconhecimento.com.br/гражданскоестроительство/конструкционного-бетона 


\begin{tabular}{|l|l|l|l|}
\hline Стандартный ход & 18,1 & 21,0 & 30,3 \\
\hline Tире с 10\% серым & 14,6 & 18,0 & 19,6 \\
\hline Tире с 20\% серым & 15,2 & 18,3 & 20,2 \\
\hline Tире с 30\% серым & 14,6 & 18,5 & 19,8 \\
\hline
\end{tabular}

Источник: Автор (2021).

Полученными результатами было подтверждено, что дозировки с использованием котловой золы показали более низкую прочность на сжатие, чем стандартная черта, принятая во всех проверенных возрастах. Среднее падение прочности на сжатие следов, использующих золу котла, по отношению к стандартному ходу было представлено, как показано в таблице 7.

Таблица 7 - Процент снижения сопротивления сжатию по отношению к стандартному ходу

\begin{tabular}{|l|c|c|c|}
\hline $\begin{array}{l}\text { Черта } \\
\text { характера/Возраст }\end{array}$ & $\mathbf{7}$ дней & $\mathbf{1 4}$ дн. & $\mathbf{2 8}$ дн. \\
\hline Тире с 10\% серым & $19 \%$ & $14 \%$ & $35 \%$ \\
\hline Tире с 20\% серым & $16 \%$ & $13 \%$ & $33 \%$ \\
\hline Тире с 30\% серым & $19 \%$ & $12 \%$ & $35 \%$ \\
\hline
\end{tabular}

Источник: Автор (2021).

Было отмечено, что во всех признаках с использованием золы процент падения прочности на сжатие по отношению к стандартному ходу вел себя аналогично независимо от используемого содержания замещения.

Что касается цвета дозированных бетонов, то было установлено, что как в свежем, так и в закаленном состоянии содержание очень мелкодисперсного заполнителя золой котла явно влияло в этом визуальном аспекте, поскольку изза того, что цвет золы котла был похож на цвет портландцемента, бетоны с

$\mathrm{RC}: 97183$

Доступно в: https://www.nucleodoconhecimento.com.br/гражданскоестроительство/конструкционного-бетона 
более высоким уровнем использования золы были визуально представлены как бетон с более высоким расходом цемента, то есть, чем темнее цвет, тем выше принятое замещающее содержимое.

\section{3. ОКОНЧАТЕЛЬНЫЕ СООБРАЖЕНИЯ}

Зола промышленного котла была классифицирована как легкая и с гранулометрическим диапазоном немного ниже очень тонкого диапазона, обе классификации применяются к агрегатам, поэтому ее применение было заключено как легкий агрегат и очень тонкий.

При увеличении содержания в дозировке замены заполнителя промышленным котлом наблюдалось влияние на обрабатываемость бетона, наблюдаемое за счет уменьшения начального выброса и конечного рассеяния. Поэтому был сделан вывод о важности принятия метода частичной замены заполнителя для использования промышленной котловой золы, поскольку была принята тотальная замена заполнителя, возможно, это оказало бы еще большее влияние на это свойство бетона в свежем состоянии.

Сделан вывод о важном вкладе добавки суперпластификатора в дозировки с использованием промышленной котельной золы, с целью компенсации потери обрабатываемости, вызванной использованием котловой золы. Было достигнуто понимание, что с помощью пластифицирующих добавок невозможно достичь удовлетворительной обрабатываемости в бетонах, дозированных зольной промышленной котлой, из-за характера золы и ее большой удельной поверхности, что приводит к более высокому расходу воды в дозировках.

Относительно плотности был сделан вывод о том, что при замещении агрегата зольной промышленной котлой наблюдалось снижение плотности, связанное с увеличением замещающего содержания, то есть чем выше содержание замещения заполнителя промышленным котлом золы, тем ниже проверяемая

$\mathrm{RC}: 97183$

Доступно в: https://www.nucleodoconhecimento.com.br/гражданскоестроительство/конструкционного-бетона 
плотность. Было сочтено очень важным в будущих дозировках наблюдать влияние, вызванное использованием промышленной котловой золы в дозировках по отношению к этому свойству бетона.

Показатели прочности на сжатие бетонов, дозированных промышленной котловой золой, были одинаковыми независимо от вариаций замещающего содержания заполнителя. Однако произошло снижение этого свойства по отношению к стандартному признаку, то есть без использования остатка. Поэтому это снижение резистентности следует учитывать в будущих дозировках, когда речь идет о дозировке по сравнению с использованием остатков.

Таким образом, был сделан вывод о целесообразности использования промышленной котловой золы при измерении конструкционного бетона, поскольку были достигнуты удовлетворительные характеристики в отношении обрабатываемости и производительности прочности на сжатие по нормативным параметрам. Таким образом, благодаря этому исследованию удалось выявить исходное поведение бетона, дозированного золой котла, и доказать целесообразность использования этого остатка.

Подразумевается, что необходимо будет продолжить исследования по усовершенствованиям, обеспечивающим хорошие показатели бетона в свежем и затвердевшемом состоянии, а также в течение срока службы зданий.

\section{ИСПОЛЬЗОВАННАЯ ЛИТЕРАТУРА}

Associação brasileira de normas técnicas. NBR 11579: Cimento Portland Determinação do índice de finura por meio da peneira 75 um ( $n^{\circ}$ 200). Rio de Janeiro, 2012.

Associação brasileira de normas técnicas. NBR 15823-2: Concreto autoadensável: Parte 2 - Determinação do espalhamento, do tempo de escoamento

$\mathrm{RC}: 97183$

Доступно в: https://www.nucleodoconhecimento.com.br/гражданскоестроительство/конструкционного-бетона 
e do índice de estabilidade visual - Método do cone de Abrams. Rio de Janeiro, 2017.

Associação brasileira de normas técnicas. NBR 16889: Concreto - determinação da consistência pelo abatimento do tronco de cone. Rio de Janeiro, 2020.

Associação brasileira de normas técnicas. NBR 5738: Concreto - procedimento para moldagem e cura de corpos de prova. Rio de Janeiro, 2016.

Associação brasileira de normas técnicas. NBR 5739: Concreto - ensaio de compressão em corpos de prova cilíndricos. Rio de Janeiro, 2018.

Associação brasileira de normas técnicas. NBR NM 248: Agregados - Determinação da composição granulométrica. Rio de Janeiro, 2003.

Associação brasileira de normas técnicas. NM 52: Agregados - Determinação da massa unitária e volume de vazios. Rio de Janeiro, 2009.

Associação brasileira de normas técnicas. NBR 9833: Concreto fresco Determinação da massa específica, do rendimento e do teor de ar pelo método gravimétrico. Rio de Janeiro, 2008.

Bauer, Luiz Alfredo Falcao. Materiais de construção. Rio de Janeiro: LTC, 2008.

Cavalcante, Zedequias Vieira. A Importância da Revolução Industrial no Mundo da tecnologia. Unicesumar . Maringá, 2011. Encontro Internacional de Produção Científica. Disponível em: https://www.unicesumar.edu.br/epcc-2011/wpcontent/uploads/sites/86/2016/07/zedequias_vieira_cavalcante2.pdf. Acesso em: 10 abr. 2021.

Ganzala, Gabryelly Godois. A Industrialização, impactos ambientais e a necessidade de desenvolvimento de políticas ambientais sustentáveis no século XXI. 2018. Centro Universitário Internacional - UNINTER. Disponível em:

$\mathrm{RC}: 97183$

Доступно в: https://www.nucleodoconhecimento.com.br/гражданскоестроительство/конструкционного-бетона 
https://repositorio.uninter.com/bitstream/handle/1/295/1355104\%20\%20GABRYELLY\%20GODOIS\%20GANZALA. pdf?sequence=1\&isAllowed=y. Acesso em: 4 abr. 2021.

MEHTA, P. K. e MONTEIRO, P. J. M. Concreto: Estrutura, Propriedades e Materiais. São Paulo: Editora Pini, 1994.

Neville, Adam Matthew. Propriedades do concreto. São Paulo: Editora Pini, 1997.

Представлено: Август 2021 года.

Август: Сентябрь 2021 года.

RC: 97183

Доступно в: https://www.nucleodoconhecimento.com.br/гражданскоестроительство/конструкционного-бетона 